\title{
RANCANGAN BANGUN SISTEM INFORMASI INVENTORY DAN PENJUALAN PADA PT. PUTRA KAROMAH SEJAHTERA
}

\author{
Wibowo Ilham Munandar ${ }^{1}$, Forkas Tiroy Santos Butarbutar ${ }^{2}$ \\ ${ }^{1,2}$ Universitas Indraprasta PGRI \\ Jalan Raya Tengah Nomor 80, Kelurahan Gedong, Pasar Rebo, Jakarta Timur \\ 1.Wibowoilham35899@gmail.com,2ftsb43dharma@gmail.com
}

\begin{abstract}
ABSTRAK
Sistem informasi inventory dan penjualan merupakan salah satu aktifitas yang di miliki sebuah perusahaan ataupun usaha yang bergerak di bidang penjualan dan pembelian agar dapat mengolah data persediaan barang, dan data transaksi barang yang dapat di lakukan secara efisien, diketahui penginputan dan pengolahan data pada sistem inventory dan penjualan di PT.Putra Karomah Sejahtera sendiri masih menggunakan sistem penginputan dan pengolahan data secara manual seperti lamanya pencatatan barang masuk dan keluar, mencari data produk, pembelian produk tidak terkontrol dan juga sering terjadinya kesalahan pada proses pembuatan laporan dalam perhitungan dan persediaan stok barang yang masih kurang efektif maupun pembayaran yang masih menggunakan nota tulis. Untuk dapat mengolah data yang jumlah cukup banyak maka diperlukan lah alat khusus yang dapat menanganinya oleh sebab itu komputer lah yang menjadi pilihan yang tepat dari berbagai sisi. Mulai dari sisi kecepatan, ketelitian dan keakuratan yang memilikinya dengan bentuk piranti lunak yang mendukunya, maka dari itu dibuat lah sebuah rancangan bangun sistem informasi inventory dan penjualan dengan menggunakan metode pengembangan sistem air terjun atau yang bisa disebut dengan Waterfall yang melalui beberapa proses tahapan yaitu: requirement, design, implements, verification dan maintenance. Hasil dari penelitian ini ialah membangun sebuah aplikasi yang mampu membantu proses transaksi lebih mudah dan efisien yang dapat membantu pihak PT. Putra Karomah Sejahtera dalam melakukan kegiatan usahanya.
\end{abstract}

Kata Kunci: Rancangan, Informasi, Sistem, Inventory dan Penjualan

\begin{abstract}
Inventory and sales information system is one of the activities owned by a company or business engaged in sales and purchases in order to process inventory data and goods transaction data that can be carried out efficiently, known as input and data processing in the inventory system and Sales at PT. Putra Karomah Sejahtera itself still uses manual input and data processing systems such as the duration of recording incoming and outgoing goods, searching for product data, uncontrolled product purchases, and also frequent errors in the reporting process in calculations and inventory stock items that are still less effective or payments that still use written notes. To be able to process a large amount of data, a special tool is needed that can handle it, therefore the computer is the right choice from various sides. Starting from the speed, accuracy, and accuracy that has it with the form of software that supports it, therefore a design is made for an inventory and sales information system using the waterfall system development method or what can be called Waterfall which goes through several stages, namely: requirements, design, implements, verification, and maintenance. The result of this research is to build an application that can help the transaction process more easily and efficiently which can help PT. Putra Karomah Sejahtera in carrying out its business activities.
\end{abstract}

Key Word: Design, Information, System, Inventory and Sales

\section{PENDAHULUAN}

Melihat pada eraperkembangan teknologi dan ilmu pengetahuan teknologi pada saat ini, dirasakan sudah semakin berkembang dengan pesat terbukti dengan manusia tidak bisa terlepas dengan teknologi yang ada saat ini. Pada era persaingan dagang bebas saat ini dibutuhkan pemrosesan data yang lebih cepat, tepat dan akurat. Banyak data ataupun informasi yang perlu diolah tidak dapat memungkinkan untuk menggunakan cara-cara yang manual untuk mengolahnya.

Penggunaan komputer sebagai perangkat kerja yang berguna untuk pengolahan suatu informasi dalam dunia usaha merupakan suatu hal yang harus dilakukan oleh para pelaku bisnis untuk menjalankan bisnisnya, hal ini 
sebagai salah satu strategi untuk meningkatkan aktifitas dalam bertransaksi. Penggunaan komputer dan penguasaan keterampilan dalam menggunakan software yang terintegrasi dalam proses pengolahan data akan dapat dilakukan dengan mudah dan akurat (Wahana \& Riswaya, 2014).

Diketahui proses pada sistem inventory dan penjualan pada PT. Putra Karomah Sejahtera masih menggunakan sistem yang bersifat manual seperti lamanya dalam pencari data barang yang terjual, data barang yang akan di beli dan proses pencarian data stok barang yang telah kosong didalam gudang atau yang akan habis, kegiatan pembelian barang tidak terkontrol dan sering terjadi kesalahan peroses pembuatan laporan dalam perhitungan dan persediaan stok barang yang kurang efektif atau metode pembayaran yang masih menggunakan nota tulis.

Dalam pengolahan data membutuhkan ketepatan dan ketelitian dalam proses transaksi yang terjadi dalam suatu usaha. Kebutuhan itu pula yang harus dilakukan oleh PT.Putra Karomah Sejahtera. Agar proses transaksi tersebut berjalan sesuai dengan apa yang diharapkan pemilik usaha seperti informasi stok produk, pembelian produk dan penjualan produk dapat diperoleh setiap saat dan akurat (Laila, 2011).

Oleh sebab itu sudah semestinya menggunakan aplikasi pengolahan data inventory dan penjualan untuk menghindarkan kesalahan-kesalahan yang mungkin dapat terjadi dalam penggunaan sistem manual (naufal Hay's \& Adrean, 2017), oleh karena itu diperlukan sebuah aplikasi yang dapat mambantu pekerjaan tersebut maka penulis mambangun sistem sebuah sistem informasi inventori dan penjualan yang dapat membantu pengolahan data yang terkait dengan pelaksanaan kegitan persediaan dan penjualan produk.

Berdasarkan permasalahan yang sudah diuraikan sebelumnya, penulis dapat marumuskan masalah tersebut dengan beberapa permasalahan tersebut yaitu: bagaimana cara merancang sistem pengolahan data pembelian, penjualan, pendataan produk masuk, pendataan produk keluar, stok produk dan retur pembelian produk yang terkomputerisasi lalu bagaimana cara mengimplementasikan sebuah program aplikasi dapat meningkatkan efisiensi kerja dalam hal mengolah data dan bagaimana merancang sebuah sistem yang dapat menyimpan data dalam satu sumber penyimpanan yang dapat membuat sebuah sistem informasi untuk dapat menagani proses pelaporan yang tepat dan akurat.

Penelitian ini bertujuan untuk dapat merancang sebuah sistem yang di gunakan untuk melakukan proses oprasional dalam pengolahan data, informasi, transaksi sehingga proses ini tidak lagi dilakukan secara manual, membuat penyimpanan data menjadi lebih baik karena sudah tersimpan dengan baik di database melalui program aplikasi sistem informasi yang telah dirancang sehingga dapat meringankan pekerjaan untuk hal pencarian data transaksi hal ini dapat memudahkan dalam proses pekerjaan dalam hal membuat laporan barang masuk, laporan stok barang, laporan keluar barang, laporan purchas order, laporan pemesanan, laporan tarnsaksi barang keluar, dan laporan nota bayar selain itu untuk menpercepat proses pencarian data.

\section{METODE PENELITIAN}

Metode adalah suatu ilmu yang membahas tentang prosedur secara disiplin untuk menata ilmu (Anggito \& Setiawan, 2018)

Penelitian adalah suatu metode untuk menyelidiki secara terstruktur atau terorganisir untuk mencari fakta dalam menentukan sesuatu dengan kritis (Noor, 2011)

Metode penelitian yang digunakan oleh penulis adalah metode kualitatif. Metode ini merupakan suatu penelitian yang fokus pada data deskriptif berupa kata-kata tertulis atau lisan dari orang lain (Gunawan, 2013).

Agar dapat memudahkan proses pengumpulan data dalam proses perancangan sistem informasi inventory dan penjualan ini penulis menggunakan diagram arus data.

Sebelum menganalisa Penulis mengumpulkan data dengan metode pengumpulan data yaitu: Studi pustaka dengan cara pengumpulan informasi yang dicoba dengan mengambil data-data dari berbagai macam artikel, buku dan internet yang bisa di jadikan landasan untuk menganalisis suatu permasalahan. 
Dari bahan-bahan yang dikumpulkan didapat teori yang mendukung topik ini sebagai bahan untuk mengatasi dan menyelesaikan masalah ini sedang diteliti agar dapat mendukung studi pustaka tersebut penulis melakukan wawancara dengan direktur oprasional PT. Putra Karomah Sejahtera ini, yaitu Bapak Aris Munandar untuk mengetahui sistem inventory dan penjualan produk di PT. Putra Karomah Sejahtera.

Adapun langkag-langkah dalam metode penelitian Waterfall.Waterfall Model atau Classic Life Cicle merupakan model perkembangan sistem yang berdasarkan daur hidup perangkat lunak yang dapat di sebut juga dengan SDLC (Software Development Life Cycle) (Bassil, 2012). yang penulis lakukan yaitu, penulis lakukan yaitu perancangan sistem, analisa kebutuhan, disain sistem, penyusunan kode program, pengujian program, implementasi sistem, dan pemeliharaan sistem.

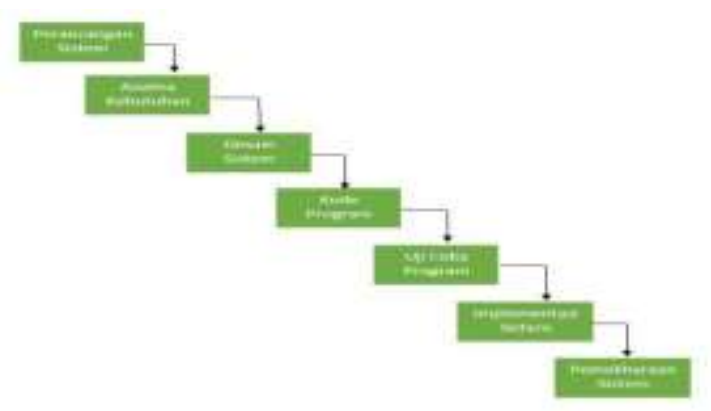

\section{Gambar 1. Metode Waterfall}

Tahapan awal dari metode waterfall sesuai gambar yang di atas yaitu perancangan sistem yang bertujuan untuk mengidentifikasi masalah. Lalu penulis menganalisa kebutuhan yang akan berproses mencari dan mendapatkan sebuah informasi. Setelah itu penulis melakukan disain tampilan aplikasi. Setelah itu melakukan penyusunan kode program, penulis melakukan pengujian program untuk mengetahui efektifitas dari aplikasi yang di buat. Setelah itu penulis memasuki tahap imolementasi sistem, dan yang terakhir pemeliharaan sistem pada admin atau divisi yang menggunakanya.

\section{HASIL PEMBAHASAN}

Berdasarkan hasil analisa dan pembahasan dalam permasalahan diatas, maka penulis membuat suatu sistem informasi inventory dan penjualan yang sudah terkomputerisasi di gunakan untuk membantu mempermudah pihak gudang dan keuangan dalam melakukan kegiatan mengolah data produk, transaksi dan membuat laporan sehingga tidak mengolah data dengan proses yang manual.

Sebelum membuat aplikasi, penulis merancangnya menggunakan DFD tertinggi yaitu diagram konteks, diagram kontek adalah diagram tingkatan atas dari sebuah diagram alur data, diagram ini hanya mewakilkan sistem yang telah dirancang secara keseluruhan (Nugrahanti, 2015), dan untuk database penulis merancang bentuk normalisasi dan ERD (Entity Relantionship Diagram)

Berikut diagram konteks yang di usulkan untuk merancang sistem informasi inventory dan penjualan pada PT. Putra Karomah Sejahtera.

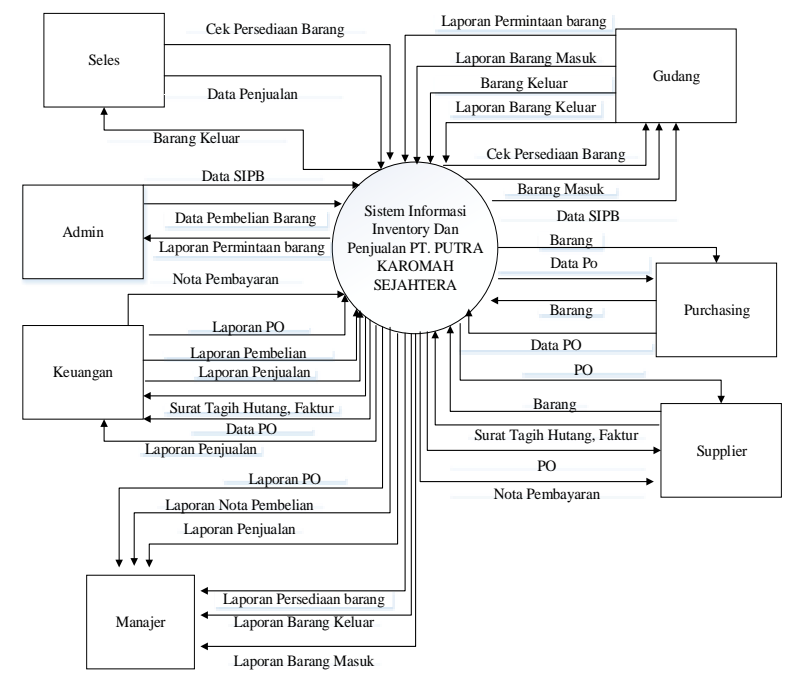

Gambar 2. Diagram Konteks

Berikut Tabel yang dihasilkan dalam pembentukan baris data sistem informasi inventory dan penjualan (Nasution et al., 2019), merupakan tahap akhir dari proses normalisasi table yang telah melalui beberapa proses. Sehingga mendapatkan baris data yang sudah optimal. 


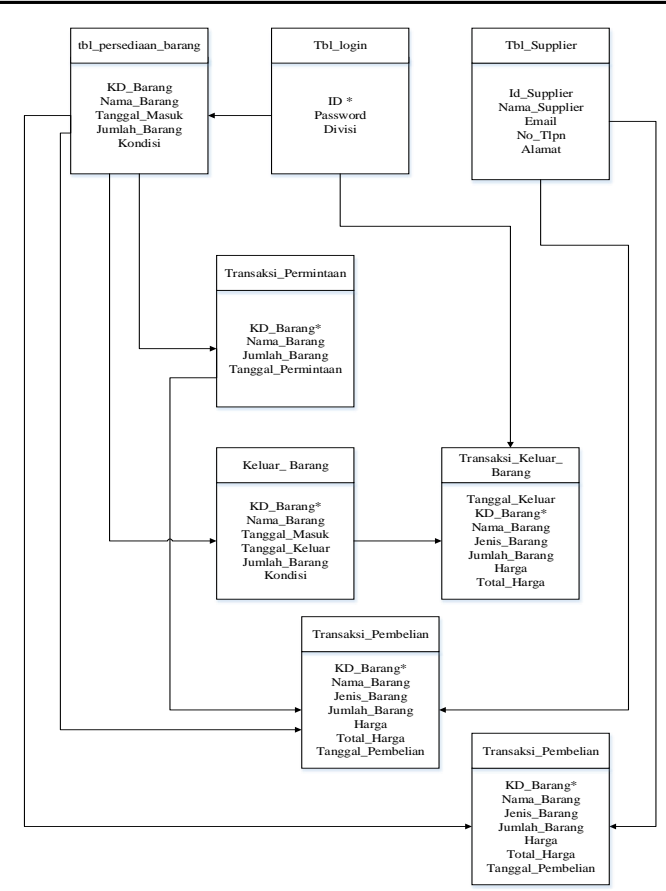

Gambar 3. Tabel Hasil Normalisasi

Peraancangan database yang digunakan untuk merancang sistem informasi inventory dan penjualan digambarkan dengan ERD (Entity Relantionship Diagram)

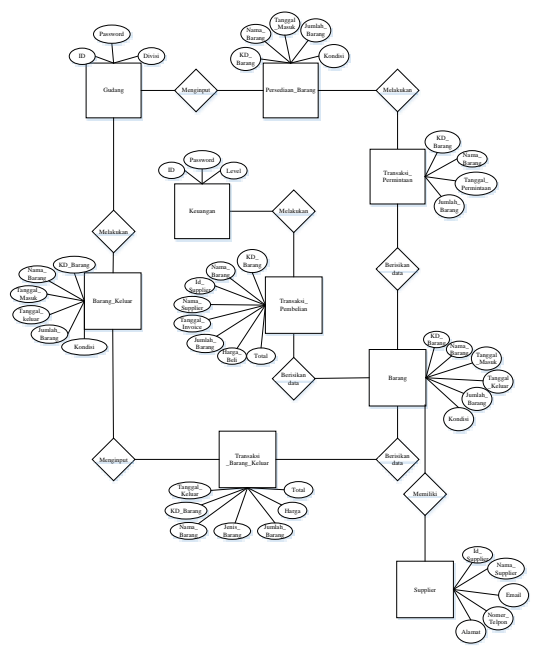

Gambar 4. ERD (Entity Relantionship Diagram)

Pada gambar diatas terdapat sembian entitas, dimana entitas gudang memiliki relasi dengan persediaan barang, barang keluar, transaksi barang keluar, barang, supplier, transaksi permintaan, transaksi pembelian, dan keuangan (Cagiltay et al., 2013) adalah sebuah pendekatan dalam perancangan baris data yang dimulai dari mengidentifikasi data terpenting yang di sebut entitas dan menghubungkan dengan entitas lain nya.
Sesuai dengan rancangan sistem yang penulis buat, maka dihasilkan sebuah aplikasi informasin inventory dan penjualan yang memudahkan para devisi yang menggunakan aplikasi ini. Berikut adalah tampilan awal layar dari aplikasi yang di hasilkan
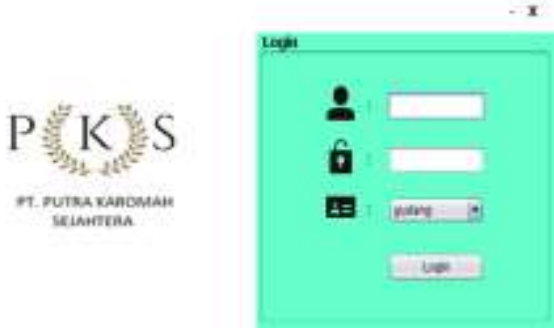

Gambar 5. Menu Login
Tampilan ini terdapat pada awal program. Menu login digunakan untuk memasuki menu utama ke dalama menu bagian gudang maupun bagian keuangan. Supaya tidak ada orang lain dapat mengakses program ini. Sehingga dalam form menu kerahasiaanya dapat terjaga dengan baik. Apabila pengguna dapat memasukan username, password dan divisi dengan benar dan tepat, maka menu utama akan tampil di program.

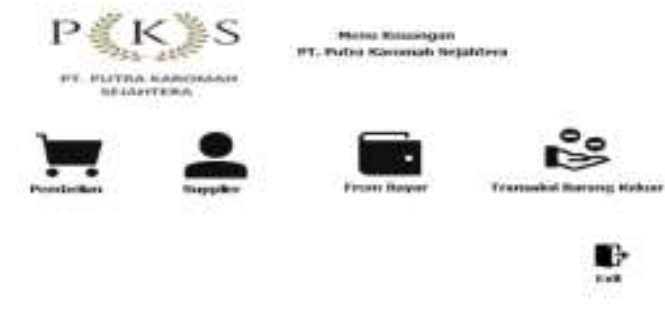

Gambar 6. Menu Keuangan

Tampilan layar menu keuangan ini dapat di tampilkan apabila pengguna telah melakukan login ke dalam devisi keuangan. pada layar utama tersedian pilihan transaksi pembelian, form supplier, master bayar, form transaksi keluar barang.

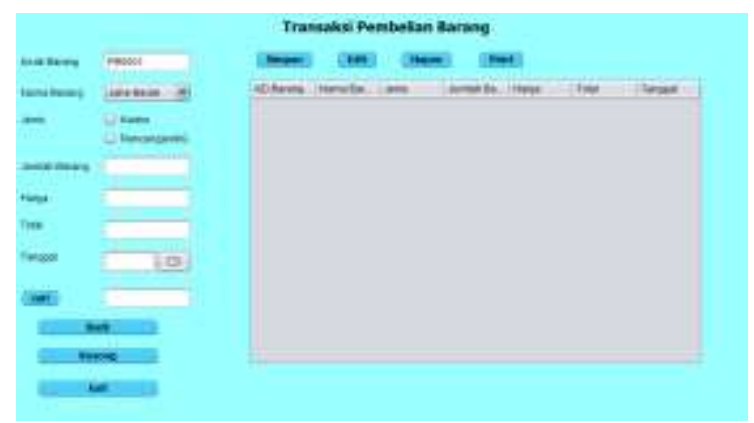

Gambar 7. Menu Transaksi Pembelian Barang 
Menu ini adalah salah satu from master yang berfungsi untuk menginput data barang yang akan di beli oleh perusahaan.

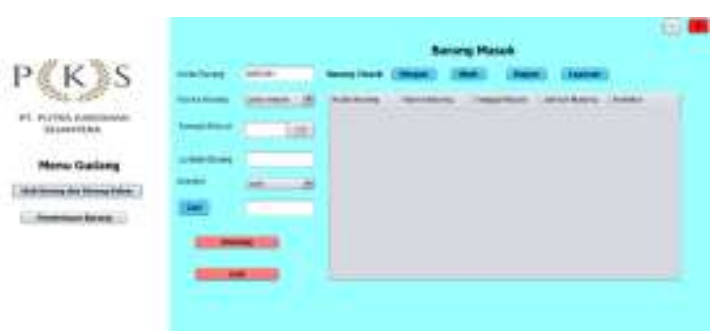

Gambar 8. Menu Barang Masuk

Tampilan ini dapat di tampilkan apabila pengguna telah melakukan logi ke bagian devisi keuangan. Menu barang masuk ini untuk menginput semua data barang yang masuk kegudang untuk mendapatkan sebuah informasi tentang kode barang dan riwayat barang, yang telah masuk ke dalam gudang, dan membuat laporan barang masuk.

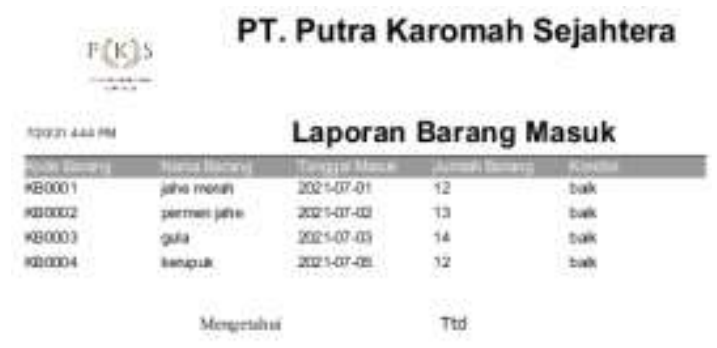

Gambar 9. Laporan Barang Masuk

Laporan ini berisikan data barang yang telah masuk kedalam gudang yang telah dibuat oleh divisi gudang.

\section{SIMPULAN DAN SARAN}

Dengan dibuatnya sistem informasi pengolahan data inventory dan penjualan yang terkomputerisasi ini semua kegiatan yang berhubungan dengan olah data inventory dan penjualan dapat berjalan dengan baik dan lancar. Dan dengan adanya aplikasi ini diharapkan akan mempermudah pendataan dan penyimpanan data inventory dan penjualan kecepatan dan ketepatan informasi. Kecepatan dan ketepatan hasil perancangan ini juga membutuhkan partisipasi aktif dari pemakai sistem, terutama kedisiplinan para pelaksana yang menangani secara langsung pada sistem yang dirancang. Dengan adanya jasa komputer sebagai alat bantu, penulis mempunyai simpulan dengan menggunakan sistem ini yaitu, pengolahan data inventory dan penjualan pada PT. Putra Karomah Sejahtera lebih efektif, cepat dan terkonsep. Data dapat tersimpan dengan aman dan pencarian data lebih mudah. Pembuatan laporan lebih mudah.

Sejalan dengan sistem usulan yang penulis buat, maka demi tercapainya tujuan dan sasaran yang diharapkan, maka penulis dapat memberikan saran yaitu, sistem informasi pengolahan data inventory dan penjualan ini dapat dikembangkan kembali dalam hal design atau penambahan database sesuai kebutuhan intansi ke depannya. Sistem informasi pengolahan data inventory dan penjualan ini haruslah didukung oleh sistem yang disiplin dan peraturan yang baik sesuai ketetapan bersama agar dapat berjalan dengan semestinya. Adanya Sistem informasi pengolahan data inventory dan penjualan ini diharapkan mampu memberikan manfaat bagi instansi. Penulis menyadari bahwa masih banyaknya kekuarangan dalam pembuatan sistem informasi pengolahan data inventory dan penjualan ini. Maka dari itu penulis berharap sistem ini dapat dikembangkan lebih baik lagi dan mendapatkan saran yang lebih baik untuk penulis. Demikian kesimpulan dan saran yang dapat penulis sampaikan, semoga skripsi ini dapat bermanfaat bagi penulis sendiri, dan pembaca.

\section{DAFTAR PUSTAKA}

Anggito, A., \& Setiawan, J. (2018). Metodologi penelitian kualitatif. $\mathrm{CV}$ Jejak (Jejak Publisher).

Bassil, Y. (2012). A simulation model for the waterfall software development life cycle. ArXiv Preprint ArXiv:1205.6904.

Cagiltay, N. E., Tokdemir, G., Kilic, O., \& Topalli, D. (2013). Performing and analyzing non-formal inspections of entity relationship diagram (ERD). Journal of Systems and Software, 86(8), 2184-2195.

Gunawan, I. (2013). Metode penelitian kualitatif. Jakarta: Bumi Aksara, 143.

Laila, N. (2011). Sistem informasi pengolahan data inventory pada toko buku studi CV. Aneka Ilmu semarang. Jurnal Teknik 
Elektro, 3(1), 16.

Nasution, D. A., Khotimah, H. H., \& Chamidah, N. (2019). Perbandingan Normalisasi Data untuk Klasifikasi Wine Menggunakan Algoritma K-NN. CESS (Journal of Computer Engineering, System and Science), 4(1), 78-82.

naufal Hay's, R., \& Adrean, R. (2017). Sistem Informasi Inventory Berdasarkan Prediksi Data Penjualan Barang Menggunakan Metode Single Moving Average Pada CV. Agung Youanda. ProTekInfo (Pengembangan Riset Dan Observasi Teknik Informatika), 4, 29-33.

Noor, J. (2011). Metodologi penelitian: skripsi. tesis, disertasi, dan karya ilmiah.

Nugrahanti, F. (2015). Perancangan Sistem Informasi Inventory Sparepart Mesin Fotocopy Dengan Menggunakan Visual Delphi 7. STT Dharma Iswara Madiun, 2(9).

Wahana, A., \& Riswaya, A. R. (2014). Perancangan Aplikasi Pengolahan Data Report Penjualan. Jurnal Computech \& Bisnis, 8(1), 25-34. 